\title{
Synergies and trade-offs between governance and costs in electricity system transition
}

\section{Authors:}

Evelina Trutnevyte ${ }^{1,2 *}$, Neil Strachan ${ }^{1}$, Paul E. Dodds ${ }^{1}$, Danny Pudjianto ${ }^{3}$, Goran Strbac $^{3}$

* Corresponding author, UCL Energy Institute, trutnevyte@sccer-soe.ethz.ch, phone +41446338705

${ }^{1}$ University College London, UCL Energy Institute, 14 Upper Woburn Place, London WC1H 0NN, United Kingdom

${ }^{2}$ ETH Zurich, Swiss Competence Center for Energy Research - Supply of Electricity, Sonneggstrasse NO F061.1, 8092 Zurich, Switzerland

${ }^{3}$ Imperial College London, South Kensington, London SW7 2AZ, United Kingdom

\section{Citation:}

Trutnevyte, E., Strachan, N., Dodds, P., Pudjianto, D., Strbac, G. Synergies and trade-offs between governance and costs of electricity system transition. Energy Policy 2015, 85, 170-181. 


\section{Abstract}

Affordability and costs of an energy transition are often viewed as the most influential drivers. Conversely, multi-level transitions theory argues that governance and the choices of key actors, such as energy companies, government and civil society, drive the transition, not only on the basis of costs. This paper combines the two approaches and presents a cost appraisal of the UK transition to a low-carbon electricity system under alternate governance logics. A novel approach is used that links qualitative governance narratives with quantitative transition pathways (electricity system scenarios) and their appraisal. The results contrast the dominant market-led transition pathway (Market Rules) with alternate pathways that have either stronger governmental control elements (Central Co-ordination), or bottom-up proactive engagement of civil society (Thousand Flowers). Market Rules has the lowest investment costs by 2050 . Central Co-ordination is more likely to deliver the energy policy goals and possibly even a synergistic reduction in the total system costs, if policies can be enacted and maintained. Thousand Flowers, which envisions wider participation of the society, comes at the expense of higher investment and total system costs. The paper closes with a discussion of the policy implications from cost drivers and the roles of market, government and society.

\section{Keywords}

Costs, investment, governance, electricity, low-carbon transition, socio-technical transitions

\section{Introduction}

In 2008, the United Kingdom (UK) was the first G20 economy to adopt an ambitious, legally-binding target to reduce its greenhouse gas emissions from the energy sector by $80 \%$ in 2050 , as compared to the levels of 1990 . Multiple studies showed that this target could be achieved at least cost through an early transition to low-carbon electricity generation, which would then facilitate the electrification of heating and transport (Anandarajah et al., 2009; Ekins et al., 2011; Williams et al., 2012). The UK Department of Energy and Climate Change (2012) estimates that $£ 110$ billion of investment (US $\$ 170$ billion) by 2020 is 
needed in the UK electricity generation, transmission and distribution system. Existing concerns about the costs and affordability of such a transition have been amplified by the global financial crisis in 2007-2008. Such concerns play a significant role in UK's recent Electricity Market Reform (DECC, 2012). In particular, the levels of investment needed (and who will pay for them) are highly debated (DECC, 2014a; Ernst \& Young, 2009; LSE, 2012; National Grid, 2013b; Ofgem, 2009, 2010). In this context, this paper appraises the investment and total system costs of the UK transition to a low-carbon electricity system from 2010 to 2050 .

In a parallel track to this cost-focused debate, a multi-level perspective to socio-technical transitions has been developed. It focuses on governance and the choices of key system actors, such as electricity companies, government and civil society (Geels, 2002; Geels and Schot, 2007). The links between cost drivers and governance have been conceptually discussed. As compared to the stategoverned electricity system, market rationale can improve the economic efficiency of the system and thus reduce the total system costs (Goldthau, 2012; Helm, 2003). Lately, market rationale has been challenged because it may not deliver high investment levels required for climate change mitigation and supply security (Bolton and Foxon, 2015; Goldthau, 2012). Even if the government could incentivize higher investment levels, this could increase the total system costs and feed back to affordability concerns. Such dynamic changes in governance have been retrospectively shown to substantially influence the energy system transition (Arapostathis et al., 2013; Pearson and Watson, 2011), but they have been barely analysed on quantitative basis. Existing studies on electricity system costs account for parametric uncertainties, such as economic growth and emission mitigation efforts (Ernst \& Young, 2009; LSE, 2012; National Grid, 2013b; Ofgem, 2009, 2010), deployment levels of specific technologies (Ernst \& Young, 2009; Hara, 2014), and supply security requirements (Ernst \& Young, 2009). However, limited efforts were dedicated to quantitative, modelling-based analysis of the role of governance. This paper primarily focuses on the implications of alternative governance pathways on the UK's electricity system transition and its costs. 
Quantitative modelling and cost appraisal of the electricity system transition under different governance pathways is a challenging task because our knowledge of governance is often of a conceptual and experiential nature (Hughes and Strachan, 2010; Pfenninger et al., 2014; Trutnevyte et al., 2014). For this reason, a story-and-simulation approach is appropriate (Alcamo, 2008; Schweizer and Kriegler, 2012; Swart et al., 2004; Trutnevyte et al., 2014; Trutnevyte et al., 2012). Qualitative governance narratives are linked with quantitative electricity system transition pathways (scenarios), and a cost appraisal is subsequently performed. Qualitative narratives allow for capturing the governance arrangements, decisions of the key actors and broader contextual developments that are often ignored in purely quantitative studies (Trutnevyte et al., 2014). Quantitative modelling and assessment allows for rigorous and internally consistent quantification of these narratives and their implications.

The cost appraisal, presented in this paper, is part of the Realising Transition Pathways project, funded by the UK Engineering and Physical Sciences Research Council. In this project, an interdisciplinary research team from nine UK universities investigates what needs to be done to achieve the UK electricity system transition that successfully addresses the energy policy 'trilemma', i.e. simultaneous delivery of low-carbon, secure and affordable energy services. In the preceding Transition Pathways project three narratives of this UK transition under alternate governance logics were developed: Market Rules, Central Co-ordination and Thousand Flowers (Foxon, 2013; Foxon et al., 2010; Hammond and Pearson, 2013). The Market Rules narrative represents the market-dominated governance, where the choices of electricity companies that interact with the national policy framework shape the electricity system transition. The Central Co-ordination narrative assumes the dominant role of the national government in delivering the low-carbon system. The Thousand Flowers narrative envisions civil society becoming the leading change agent through the deployment of bottom-up solutions.

These three governance narratives have already been addressed from the perspectives of technical feasibility (Barnacle et al., 2013; Pudjianto et al., 2013), environmental impacts (Hammond et al., 2013; Hammond and O'Grady, 2013), 
supply security (Boston, 2013), and uncertainty and future branching points (Foxon et al., 2013; Hughes et al., 2013). In the project to date, the economic perspective has not been systematically considered using quantitative modelling approach and has only been discussed conceptually (Foxon, 2013; Hammond and Pearson, 2013). Thus, this paper adds this missing economic perspective to the Realising Transition Pathways project. In comparison to the other project's activities, this is the most comprehensive cost appraisal with the widest system boundaries (electricity generation, transmission and distribution, electric heating and transport, and cost savings due to replaced fossil fuel based heating and transport). Trutnevyte et al. (2014) present further efforts to combine eight technical feasibility, economic and environmental models to assess the Central Co-ordination narrative from a quantitative perspective beyond economics. Trutnevyte (2014) experiments with modelling of different electricity generation portfolios for the three governance narratives. But neither of the two latter studies appraises the costs of the narratives in such a detailed and broad manner.

The paper is structured as follows: Section 2 describes the methodology and introduces the Realising Transition Pathways narratives; Section 3 summarises and discusses the cost appraisal results; Section 4 interprets the results in terms of the previous studies, discusses the limitations and identifies future research needs; and Section 5 concludes with policy insights from the contrast between cost appraisal versus governance approaches to analysing long-term electricity transitions.

\section{Methodology and the three governance narratives}

The analysis starts with the qualitative governance narratives that describe governance arrangements, choices of the key actors and the respective energy transitions (Section 2.1). Each qualitative narrative is then 'translated' into a quantitative electricity system transition pathway (Section 2.2). This pathway shows the detailed, technically-elaborated evolution of the electricity demand and supply, including the technology choices of electricity companies and consumers. The costs of the quantitative pathways-that are the 
representations of the qualitative governance narratives-are finally appraised and compared (Section 2.3).

\subsection{Governance narratives}

The three governance narratives, described in detail by the Transition Pathways project (2012) and by Foxon (2013), define alternate UK transitions to a low-carbon electricity system, its governance arrangements and the choices of key system actors from 2010 to 2050. The narratives distinguish between three ideal-types of governance logics (Figure 1): market logic in the Market Rules narrative, government logic in the Central Co-ordination narrative, and the civil society logic in the Thousand Flowers narrative. While these narratives picture the ideal-type governance logics, the UK electricity system governance in reality will likely be a hybrid of all these three logics with different strengths. Today's governance is argued to be a hybrid of the Market Rules and Central Coordination narratives (Bolton and Foxon, 2013; Goldthau, 2012).

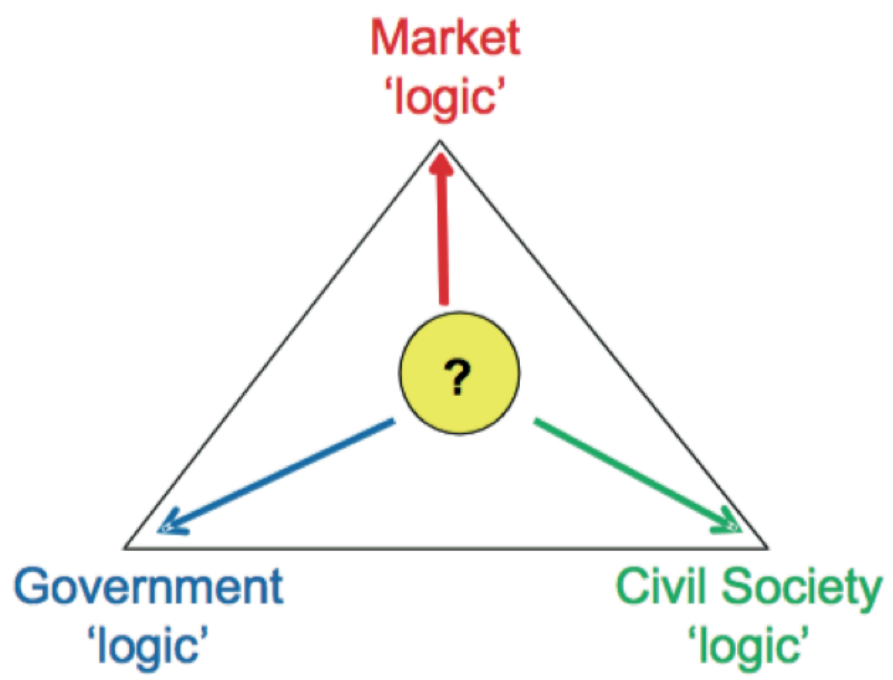

Figure 1. Three ideal-types of the UK electricity system governance logics.

Source: J. Burgess and T. Hargreaves; reproduced from Foxon (2013).

\subsubsection{Market Rules narrative}

The Market Rules narrative envisions that market logic will dominate the UK electricity system transition. Large electricity companies and other market 
actors will deliver the transition, when freely interacting with the policy framework. This policy framework will set broad goals and implementation mechanisms, but otherwise will minimise its interference. In this narrative, a strong worldwide consensus on mitigating climate change and UK-wide concerns on supply security will lead to the focus on large-scale power plants with low or zero-carbon emissions, such as coal and gas with carbon capture and storage (CCS), nuclear, offshore and onshore wind. Small-scale technologies will not emerge in such a market. The large electricity companies will see the highly electrified energy system as a business opportunity and thus there will be a substantial increase in the use of electric heating and plug-in hybrid electric vehicles (PHEV). Consumers will play a passive role, with regards to voluntary energy demand reductions and deployment of small-scale generators. Carbon price floor, renewable obligations, capacity mechanisms and other policy instruments introduced by the government will determine the evolution of the system, but the investment context will be comparatively risky due to the high degree of freedom in the market.

\subsubsection{Central Co-ordination narrative}

The Central Co-ordination narrative envisions a greater direct role for the government, working closely with large electricity companies in delivering the aspired electricity system transition. After some progress and a moderate worldwide commitment in international climate negotiation, UK will step forward by establishing a Strategic Energy Agency. This agency will steer the electricity system transition towards the desirable generation portfolio by issuing contracts for 5-year tranches to specific types of power plants in order to reduce investment risk. These contracts will be used for large-scale generation, such as nuclear, offshore wind and coal with CCS, while small-scale electricity generators will receive agreements to purchase their excess electricity after 2038 only. The consumers will play a passive role, but the government will initiate major energy efficiency programmes to reduce demand by means that require little direct consumer engagement and increase the uptake of electric vehicles (EVs), PHEVs and electric heating. The evolution of the electricity 
system will thus be primarily determined by these central contracts for specific technologies.

\subsubsection{Thousand Flowers narrative}

The Thousand Flowers narrative envisions households, communities, local governments and non-governmental organisations to play an active role through local, bottom-up initiatives. Such transition is enabled through the matching UK policy framework that is less coupled to the international scene. The initial government feed-in tariffs for small-scale technologies will gradually put more pressure on energy companies to increase efficiency of their consumers. This will lead to the successful market entrance of energy service companies (ESCOs) and, to some extent, large electricity companies adopting the ESCO business model; the ESCO model is described in more detail by Pantaleo et al. (2014). As a result, there will be a substantial deployment of micro- and community-scale combined heat and power (CHP) plants, solar photovoltaic (PV) elements and onshore wind. Due to growing awareness of the climate change impacts, electricity consumers will voluntarily adopt various technological and behavioural end-use demand reduction measures, including EVs. Due to the success of these bottomup initiatives, the ESCO model and the government support, the investment context will favour small-scale generation.

\subsection{Quantitative transition pathways}

Each narrative is 'translated' into a quantitative electricity system transition pathway (scenario). As these quantitative pathways are tightly linked to the qualitative narratives, they already include implications of governance and decisions of the key actors in terms of technology choices and electricity demand evolution. As described by Foxon (2013), the Transition Pathways Technical Elaboration Working Group iteratively developed these quantitative pathways by merging insights from two electricity supply models and one demand model (Barnacle et al., 2013; Barton et al., 2013; Robertson et al., 2012a; Robertson et al., 2012b). In the typology of energy models (Bhattacharyya and Timilsina, 2010), these three models fall in the accounting framework category. One of the 
supply models had 1-hour temporal resolution, while the other supply model and the demand model had 1-year resolution (Trutnevyte et al., 2014). They investigated only technical feasibility of the pathways and used predefined technology merit order, rather than assumptions on future costs, to model future transition. Every quantitative pathway describes complete portfolios of electricity supply and demand technologies, including annual electricity demand and its structure, installed power plant capacity, and generated and imported electricity flows until 2050, in 5-year intervals (Foxon, 2013). Figure 2 depicts the structure of electricity demand and supply for the three narratives, including a detailed account of electric heating and transport as well as heat produced in CHP plants.

All three pathways differ in their total electricity demand and its structure as well as in the electricity generation portfolio. In terms of the annual electricity demand, Market Rules has the highest electricity demand growth until 2050, which is primarily driven by growing industrial electricity demand. Market Rules also envisions a substantial uptake of electric resistive heating and heat pumps in domestic and commercial sectors as well as PHEV and EV, which leads to higher electricity demand. Central Co-ordination also assumes similar levels of electric heating and transport, but the industrial electricity demand stays roughly constant until 2050. Thousand Flowers has the lowest electricity demand of the three pathways because it assumes that energy consumers will adopt proenvironmental behaviours and invest in efficient energy use. Electric heating will not be adopted as widely in Thousand Flowers, but EVs would have the highest growth rate among the three pathways. 


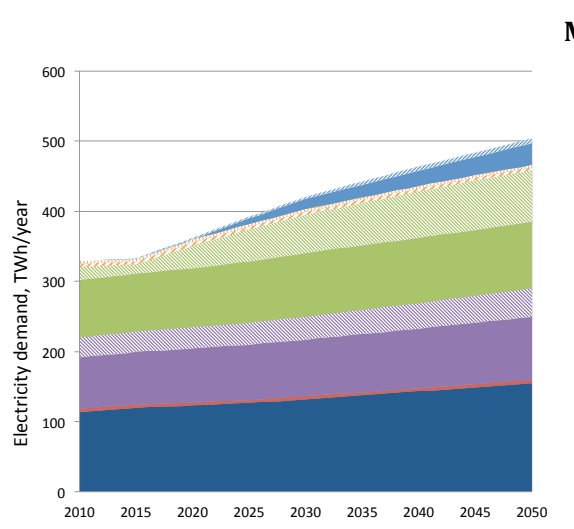

\section{Market Rules}

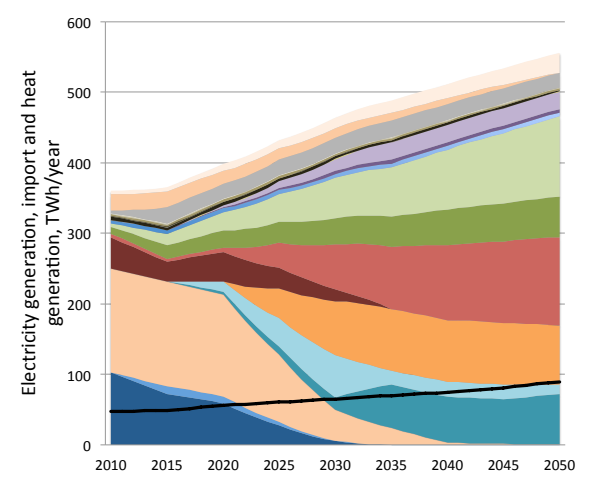

Central Co-ordination
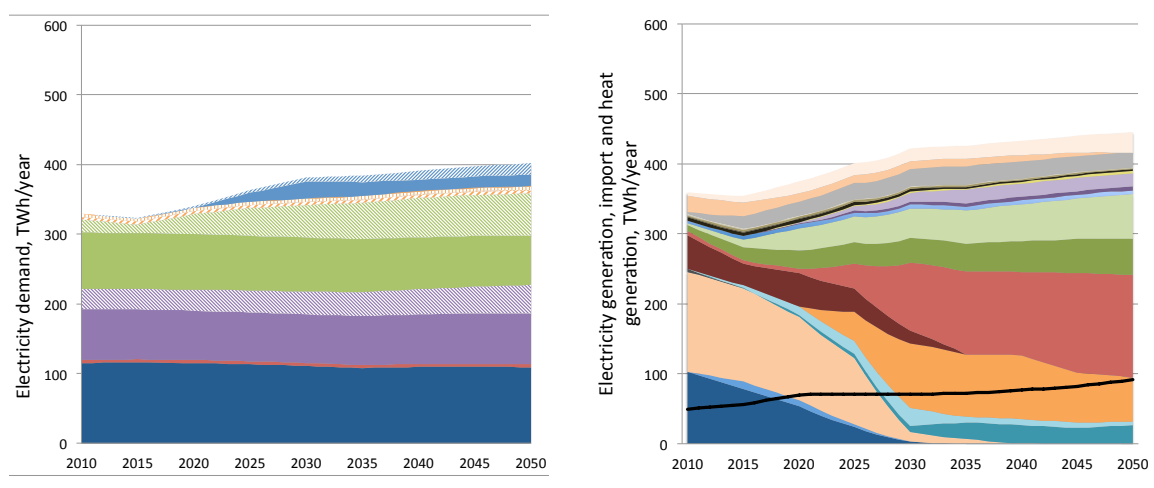

Thousand Flowers
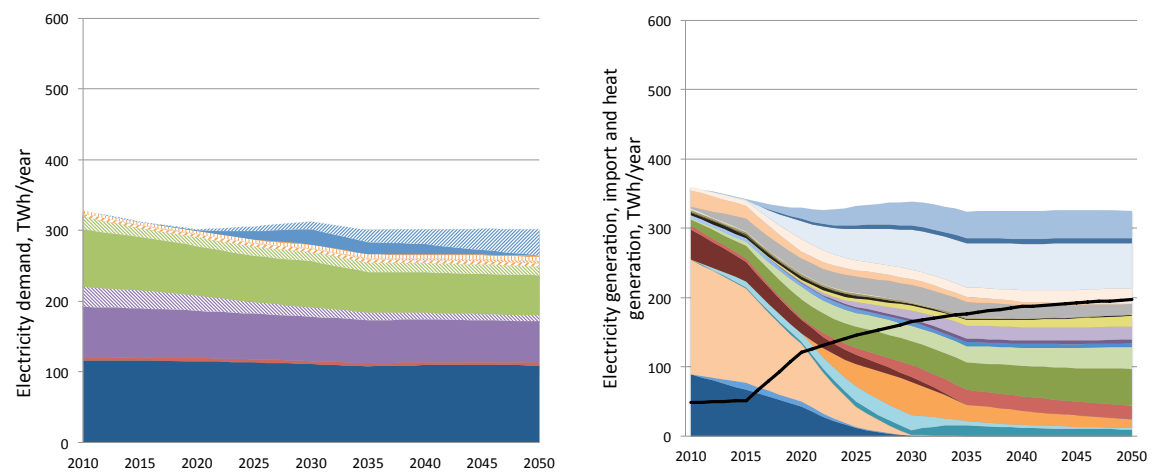

\begin{tabular}{|c|c|}
\hline Domestic/ heating & //. Transport/ EV \\
\hline Domestic/other & - Transport/ PHEV \\
\hline $\begin{array}{l}\text { NC Commercial/ } \\
\text { heating }\end{array}$ & Transport/freight \\
\hline Commercial/ other & $\begin{array}{l}\text { Transport/ } \\
\text { passenger rail }\end{array}$ \\
\hline Agriculture & NTransport/ buses \\
\hline Industry & $\begin{array}{l}\text { Transport/ non- } \\
\text { tranction }\end{array}$ \\
\hline
\end{tabular}

$$
\begin{aligned}
& \text { Hydro - reservoir } \\
& \text { Wind - offshore } \\
& \text { Wind - onshore } \\
& \text { Nuclear - new } \\
& \text { Nuclear - existing } \\
& \text { Gas with CCS } \\
& \text { Coal IGCC with CCS } \\
& \text { Coal ASC with CCS } \\
& \text { Oil } \\
& \text { Gas OCGT } \\
& \text { Gas CCGT } \\
& \text { Coal IGCC } \\
& \text { Coal ASC } \\
& \text { — Heat from CHPs }
\end{aligned}
$$

$$
\begin{aligned}
& \mu \text { CHP - fuel cell } \\
& -\mu \text { CHP - Stirling engine } \\
& \text { Community CHP - biogas } \\
& \text { Large CHP - renewable } \\
& \text { Large CHP - gas } \\
& \text { Interconnectors } \\
& \text { Biomass - animal and plant biomass } \\
& \text { Biomass - sewage sludge } \\
& \text { Biomass - municipal solid waste } \\
& \text { Biomass - co-firing } \\
& \text { Biomass - landfill } \\
& \text { Solar } \\
& \text { - Tidal }
\end{aligned}
$$

Figure 2. Three transition pathways in terms of annual electricity demand and supply. The graphs on the left show electricity end-use demands; the graphs on the right show the generation portfolio for each pathway. Source: data from (Foxon, 2013). 
As annual electricity demand and governance arrangements differ for the three pathways, the electricity generation portfolios differ too as described in Sections 2.1.1-2.1.3. All three pathways are assumed to meet the UK greenhouse gas emissions target by 2050 , all coal and gas power plants that are unabated (without CCS) are assumed to phase out in all three pathways.

Necessary additional detail for the cost appraisal is added to the quantitative transition pathways from Figure 2. The retirement of existing capacity and the installation of new capacity are modelled on the basis of planned capacity retirement (DECC, 2010) and, otherwise, on the basis of capacity retirement rates and technical lifetimes of power plants. Lifetime extensions and retrofitting are not considered. The predefined quantitative pathways already assumed retirement of the existing nuclear power plants (Figure 2). The UK coal power plant fleet is close to the end of its lifetime (DECC, 2010) and the substantial share of gas plants will be close to it too by the time, when CCS is assumed to get significantly deployed in the three pathways.

The pathways are disaggregated into one-year steps from 2010 to 2050 so that existing capacity retirement year and lifetimes, which are not multipliers of 5 , could be modelled more precisely. This enables capturing the investment dynamic better.

In order to evaluate the costs of transmission and distribution, these infrastructure requirements are modelled with the Holistic Approach to Power System Optimisation model (HAPSO), described by Strbac et al. (2012). HAPSO is a bottom-up, cost-minimisation model that determines the optimal transmission and distribution network, storage and interconnection requirements and their costs. The model optimises simultaneously the long-term investment and shortterm operating decisions from 2010 to 2050, including generation dispatch with one-hour resolution, demand side response, storage cycles and electricity import and export. As spatial distribution of electricity demand and generation drives the network expansion, the UK territory is divided into five regions: Scotland, north England and Wales (EW), Midlands, south EW, and London area. The UK electricity system is integrated in the European system that comprises the UK, Ireland and continental Europe. Thus, interconnectors between Scotland and 
Ireland, Scotland and Norway, Midlands and Ireland, south EW and continental Europe, and Ireland and continental Europe are considered. In order to model the infrastructure requirements of the three pathways, the quantitative electricity demand and generation assumptions from Figure 2 are enforced in HAPSO and the results of investment costs for transmission and distribution are used in the cost appraisal. As HAPSO models the electricity exchange with the rest of Europe, HAPSO's assumptions of the EU wholesale electricity prices for the UK imports are used (Supplementary Material A).

\subsection{Cost appraisal methodology and its key assumptions}

This section describes the cost appraisal methodology, including the appraisal boundaries, method, key quantitative assumptions and sensitivity analysis.

\subsubsection{Boundaries and methodology}

Three governance narratives and their respective quantitative transition pathways depict the UK transition to a low-carbon electricity system from 2010 to 2050. As they describe changes in the electricity generation portfolio and in electricity demands, the cost appraisal primarily focuses on (i) large-scale electricity generation and storage, (ii) small-scale electricity generation, (iii) electricity transmission, distribution and interconnectors with Europe, (iv) electric heating and electric transport. As electric heating and transport provide different levels of energy services for space heating, hot water and transportation, it is necessary to account for these differences between the three pathways. It is thus calculated that energy services, provided by electric heaters, heat pumps, CHPs, lead to cost savings in the current conventional technology of gas boilers. The energy services, provided by electric transport (electric rail, electric buses, PHEVs and EVs), lead to cost savings in transportation with internal combustion engine (ICE). These cost savings are then deducted from the total costs.

The cost appraisal includes investment costs, fixed and variable O\&M costs, fuels costs, financing costs, and carbon price. Investment and O\&M costs 
and the related assumptions are reported in Supplementary Material A. Fuel and financing costs are discussed in Section 2.3.2. Large-scale power plants are assumed to take part in an emission trading scheme. As all three pathways assume transition to a low-carbon system, carbon price (Table 1) is assumed equal to the carbon price floor, set by the Electricity Market Reform until 2030 (DECC, 2012), and afterwards equal to the central estimates by the UK Department of Energy and Climate Change (2011).

Table 1. Assumed carbon price, $€(2010) / \mathrm{tCO}_{2}\left[\mathrm{US} \$(2010) / \mathrm{tCO}_{2}\right]$. Year-by-year values are provided by DECC $(2011,2012)$.

\begin{tabular}{|l|l|l|l|l|l|}
\hline & 2012 & 2020 & 2030 & 2040 & 2050 \\
\hline Carbon price & 12.7 & 30.9 & 72.2 & 139.8 & 207.2 \\
& {$[19.6]$} & {$[47.8]$} & {$[111.6]$} & {$[216.1]$} & {$[320.3]$} \\
\hline
\end{tabular}

The appraisal methodology is based on an accounting framework (Bhattacharyya and Timilsina, 2010) with one-year time resolution from 2010 to 2050. The present value approach is used for appraising the investment and total system costs, because it accounts for the investment costs, when they occur rather than annualises them throughout the lifetime. In order to evaluate the present value of costs, a social discount rate of 3.5\% until 2040 and 3\% afterwards is used (European Commission, 2008; HM Treasury, 2011).

This paper also conducts a stylised comparison of the technology-specific costs and the whole generation mix costs per unit of electricity generated. This comparison is based on levelised costs of electricity (Short et al., 1995). The predefined quantitative pathways (Foxon, 2013) did not include detailed dispatch data within one year. Annual electricity generation levels are only enough to calculate levelised costs of electricity. Levelised costs do not capture the dynamics of electricity costs and prices due to dispatch effects and they blend investment and annual costs into one number that does not give any indication of investment attractiveness. Yet, levelised costs are still useful to compare technologies with different characteristics, such as investment and annual costs, lifetimes, generated electricity amounts etc. These costs are evaluated as total costs per discounted MWh of generated electricity, including investment costs, financing costs, annual O\&M costs, and annual fuel costs both with and without a 
carbon tax. With the exception of the carbon tax, the total costs exclude the effects of any policies, such as subsidies or feed-in tariffs, as the likely future implementation of such policies is unknown. For CHP, it is assumed that the heat output is sold at a price equivalent to the cost of producing heat in gas boilers, and these revenues are deducted from the total costs. The whole mix costs per unit of electricity generated are evaluated as an average of technology-specific costs, weighted according to how much electricity the different technologies generate.

The year 2010 is the reference year for this appraisal and all the costs that occur afterwards are accounted for. There is no Business as Usual or Baseline pathway. Thus, the three pathways-Market Rules, Central Co-ordination and Thousand Flowers-need to be compared with respect to each other in terms of their costs after 2010 .

\subsubsection{Sensitivity analysis}

Fossil fuel prices and financing costs are examined in the sensitivity analysis because these assumptions result in differences between the three pathways (Figure 2) and are most likely to affect the relative costs of the pathways.

Fossil fuel prices are important because the three pathways incorporate different deployment levels of fossil fuel-based electricity generation and replace different numbers of gas boilers and ICE vehicles. Low, central and high price projections for coal, gas and crude oil are taken from DECC (2013) for 20122030. For 2030-2050, the price assumptions are kept at the level of 2030, assuming that the range sufficiently reflects the uncertainty. This range between low prices, which assume decreasing oil and gas and stable coal prices, and high

prices, which assume growth of all fossil fuel prices, captures implications of various potential outcomes of the worldwide commitment to climate change mitigation. These assumptions are used to vary the prices of coal, gas (for largescale generation and gas boilers), gasoline and diesel. These projections are summarised in Table 2 . 
Table 2. Fossil fuel price assumptions for the sensitivity analysis

\begin{tabular}{|c|c|c|c|c|}
\hline & 2012 & 2020 & 2030 & 2050 \\
\hline $\begin{array}{c}\text { Crude oil, US\$(2010)/barrel } \\
\text { - Low prices } \\
\text { - Central case } \\
\text { - High prices } \\
\end{array}$ & $\begin{array}{l}106 \\
106 \\
106 \\
\end{array}$ & $\begin{array}{l}79 \\
111 \\
139 \\
\end{array}$ & $\begin{array}{l}69 \\
125 \\
181 \\
\end{array}$ & $\begin{array}{l}69 \\
125 \\
181 \\
\end{array}$ \\
\hline $\begin{array}{cl}\text { Coal, US\$(2010)/tonne } \\
\text { - } & \text { Low prices } \\
\text { - } & \text { Central case } \\
\text { - } & \text { High prices } \\
\end{array}$ & $\begin{array}{l}88 \\
88 \\
88 \\
\end{array}$ & $\begin{array}{l}87 \\
115 \\
130 \\
\end{array}$ & $\begin{array}{l}87 \\
115 \\
155 \\
\end{array}$ & $\begin{array}{l}87 \\
115 \\
155 \\
\end{array}$ \\
\hline $\begin{array}{l}\text { Gas, US\$(2010)/1000therm } \\
\text { • } \quad \text { Low prices } \\
\text { - Central case } \\
\text { • High prices }\end{array}$ & $\begin{array}{l}912 \\
912 \\
912\end{array}$ & $\begin{array}{l}627 \\
1096 \\
1534\end{array}$ & $\begin{array}{l}627 \\
1096 \\
1566\end{array}$ & $\begin{array}{l}627 \\
1096 \\
1566\end{array}$ \\
\hline
\end{tabular}

Financing costs are affected by governance and policy stability, and can therefore reveal further differences between the pathways. In this appraisal financing costs are considered as the weighted average cost of capital, which accounts for both cost of debt and equity. The cost of debt for power generation technologies in countries like the UK is on average 5-6\% (Blyth et al., 2014; Schmidt, 2014) and the cost of equity is on average 10\% (Schmidt, 2014). In the central case, all electricity generation technologies are assumed to have financing costs of 7\% in line with DECC (2014b). In reality, the cost of capital may vary substantially between different technologies. For example, riskier investments have higher interest rates and thus the costs of debt are higher (Brealey and Myers, 2000; Oxera, 2011; Schmidt, 2014). At the same time, stable policies reduce investment risks and financing costs (Oxera, 2011). In addition to the central case, three other cases are analysed (Table 3). The "Differentiated for technologies" case assumes higher financing costs for technologies with higher risks, in line with Oxera (2011). The "Differentiated for governance narratives" cases aim to capture the potential implications of governance as described in the governance narratives (Section 2.1). For example, if the Central Co-ordination narrative envisions that the newly established Strategic Energy Authority issues long-term contracts for specific types of generation to reduce investment risks, it is assumed that these types of generation would receive better interest rates and thus the financing costs would be lower. Two "Differentiated for governance narratives" cases are analysed: one with intermediate and one with strong implications of policies on the financing costs. 
All three narratives envision equally strong emphasis and related policies on end-use investments, such resistive heaters, heat pumps, transport and micro-CHPs. Thus, $7 \%$ financing costs are assumed to reflect that such investment would have a low to moderate risk level in all three pathways. All three governance narratives also consider transmission, distribution and storage as planned investment. As this investment faces low risk, a rate of $5 \%$ is assumed in line with National Grid (2013a).

Table 3. Financing cost assumptions for the sensitivity analysis

\begin{tabular}{|c|c|c|c|}
\hline & Market Rules & Central Co-ordination & Thousand Flowers \\
\hline Central case & \multicolumn{3}{|c|}{$\begin{array}{l}\text { - All generation technologies and CCS: 7\% } \\
\text { - All end-use equipment (heating, vehicles etc.): 7\% } \\
\text { - Transmission, distribution, storage: } 5 \%\end{array}$} \\
\hline $\begin{array}{l}\text { Differentiated } \\
\text { for } \\
\text { technologies }\end{array}$ & \multicolumn{3}{|c|}{$\begin{array}{l}\text { - Coal, gas, oil, onshore wind, hydro, interconnectors, large CHP with gas: } 7 \% \\
\text { - Nuclear, offshore wind, biomass, solar, large CHPs with renewables: } 9 \% \\
\text { - CCS (excl. its base plant), wave, tidal: } 10 \% \\
\text { - } \text { All end-use equipment (heating, vehicles etc.): } 7 \% \\
\text { - Transmission, distribution, storage: } 5 \%\end{array}$} \\
\hline $\begin{array}{l}\text { Differentiated } \\
\text { for } \\
\text { governance } \\
\text { narratives I }\end{array}$ & $\begin{array}{l}\text { "Differentiated for } \\
\text { technologies" case and: } \\
\text { - CCS (excl. its base } \\
\text { plant), wave, tidal } \\
\text { and nuclear: minus } \\
1 \% \\
\text { - Wind, biomass, } \\
\text { large CHPs with } \\
\text { renewables: minus } \\
2 \%\end{array}$ & $\begin{array}{l}\text { "Differentiated for } \\
\text { technologies" case and: } \\
\text { - Onshore wind, } \\
\text { biomass, large CHPs } \\
\text { with renewables, } \\
\text { community CHPs: } \\
\text { minus } 1 \% \\
\text { CCS (excl. its base } \\
\text { plant), nuclear, } \\
\text { offshore wind, wave, } \\
\text { tidal: minus } 2 \%\end{array}$ & $\begin{array}{l}\text { "Differentiated for } \\
\text { technologies" case and: } \\
\text { - } \quad \text { Nuclear, wind, } \\
\text { biomass, wave, } \\
\text { tidal, large CHPs: } \\
\text { minus } 1 \% \\
\text { - Solar, small CHPs: } \\
\text { minus } 2 \%\end{array}$ \\
\hline $\begin{array}{l}\text { Differentiated } \\
\text { for } \\
\text { governance } \\
\text { narratives II }\end{array}$ & $\begin{array}{l}\text { "Differentiated for } \\
\text { technologies" case and: } \\
\text { - CCS (excl. its base } \\
\text { plant), wave, tidal } \\
\text { and nuclear: minus } \\
1.5 \% \\
\text { - Wind, biomass, } \\
\text { large CHPs with } \\
\text { renewables: minus } \\
3 \%\end{array}$ & $\begin{array}{l}\text { "Differentiated for } \\
\text { technologies" case and: } \\
\text { - Onshore wind, } \\
\text { biomass, large CHPs } \\
\text { with renewables, } \\
\text { community CHPs: } \\
\text { minus } 1.5 \% \\
\text { CCS (excl. its base } \\
\text { plant), nuclear, } \\
\text { offshore wind, wave, } \\
\text { tidal: minus } 3 \%\end{array}$ & $\begin{array}{l}\text { "Differentiated for } \\
\text { technologies" case and: } \\
\text { - Nuclear, wind, } \\
\text { biomass, wave, } \\
\text { tidal, large CHPs: } \\
\text { minus } 1.5 \% \\
\text { - } \begin{array}{l}\text { Solar, small CHPs: } \\
\text { minus } 3 \%\end{array}\end{array}$ \\
\hline
\end{tabular}

Multiple other uncertainties may influence the electricity system transition and its costs (Hughes et al., 2013; Usher and Strachan, 2013). First, other existing analyses explore sensitivity of their results to economic growth and emission mitigation efforts (Ernst \& Young, 2009; LSE, 2012; National Grid, 2013b; Ofgem, 2009, 2010), deployment levels of specific technologies and 
security of supply requirements (Ernst \& Young, 2009). This cost appraisal cannot address these sensitivities, because electricity demand structure and generation portfolio are fixed through 'translation' of narratives into quantitative assumptions (Figure 2). Sensitivity analysis of different electricity generation portfolios for the three pathways is already explored in Trutnevyte (2014). Second, sensitivity to different carbon prices is not analysed because it would not reveal further differences among the pathways as all of these pathways reduce their emissions to similar levels (Hammond et al., 2013; Hammond and O'Grady, 2013). Third, costs of electricity generation and end-use technologies could cause greater variations in investment costs and total system costs, but such variations are already to some extent covered by the sensitivity analysis of different financing cost assumptions. For example, if technologies are supported by policies in the narrative, they will receive lower interest rates, which will reduce their costs. Fourth, sensitivity to cost assumptions for non-electric heating and transport is explored by varying fossil fuel costs. As a result, only fossil fuel costs and financing costs are examined in this paper.

\section{Results of the transition pathway cost appraisal}

\subsection{Investment costs and total system costs}

Cumulative investment costs and total system costs, evaluated using the present value approach for the three pathways from 2010 to 2020, 2030 and 2050, are summarised in Table 4. In terms of the investment costs, Market Rules requires the lowest investment costs for the system as a whole, whether the cost savings for heating and transport are included or not. Although Market Rules has the highest investment levels in electricity generation, transmission and distribution, it requires lower investment costs in electric heating equipment and electric transport. Thousand Flowers requires the highest investment costs in electricity generation, electric heating and especially in electric transport due to costly EVs. At the same time, it needs less investment in transmission and distribution. Large-scale generation drives the transmission investment costs, while distribution costs are driven by the levels of electric heating and transport 
deployed. Thousand Flowers has a substantially lower level of electric heating, while electricity from community- and micro-scale CHPs is primarily consumed at a local level. Investment costs for Central Co-ordination fall between those of the Market Rules and Thousand Flowers pathways.

Without cost savings in heating and transport, Market Rules again leads to the lowest total system costs, even if it generates more electricity than the other two pathways. If cost savings are accounted for, Market Rules does not have the lowest total costs, because its cost savings due to replaced fossil fuel alternatives in heating and transport are not as high as in other pathways. Market Rules assumes high deployment of cheaper PHEVs rather than EVs (Supplementary Material A). As PHEVs do not lead to such high fossil fuel savings as EVs, cost savings due to replaced fossil fuels in transport are not as high as in other pathways. When cost savings are considered, Central Co-ordination has the lowest cumulative total system costs, even if it does not have the lowest investment costs. Thousand Flowers has the highest total costs. When cost savings in heating and transportation are accounted for, Thousand Flowers and Market Rules perform almost exactly the same, but Market Rules has the highest electricity demand and Thousand Flowers include deployment of expensive small-scale electricity generators and, in particular, costly EVs.

In terms of the ratio between investment and total system costs for electricity generation, until 2030 Market Rules has lower share of costs that needs to be dedicated to investment as compared to the other two pathways: $18 \%$ for investment and $82 \%$ for annual costs. After 2030, Thousand Flowers has the lowest share (21\% for investment), but as Thousand Flowers include many CHPs with high fuel costs, the difference with Market Rules or Central Coordination is not large (22\% each). If costs for electricity generation, heating, and transport are accounted for, investment share for Market Rules is again the lowest (27\%-28\% for investment), while Central Co-ordination has the investment share of 32\%-35\% and Thousand Flowers - 34-35\%, which gives indication of a higher investment challenge.

Overall, depending on how the system boundaries are drawn-only generation or covering other parts of the system too-the ranking of the three pathways in terms of costs varies. Market Rules and Central Co-ordination 
perform fairly similarly across multiple cost indicators, but this is not surprising because they both focus on large-scale generation that is less costly. The pathways are relatively similar in terms of both the investment costs and total system costs, as the differences do not exceed 10\%. But such minor differences are common in cost appraisals of highly diversified energy systems. Costs of individual technologies can vary substantially, as shown in the Supplementary Material A. But when total costs of the whole system are evaluated, where multiple technologies - cheaper and more expensive ones - are simultaneously deployed, differences in the total costs of the whole system even out and are not as pronounced as differences in costs of individual technologies. 
Table 4. Investment costs and total system costs for the three governance narratives (Central case assumptions)

\begin{tabular}{|c|c|c|c|c|c|c|c|c|c|c|c|c|}
\hline & \multicolumn{6}{|c|}{ Cumulative investment costs since 2010, excluding financing costs } & \multicolumn{6}{|c|}{$\begin{array}{l}\text { Cumulative total system costs since } 2010 \text {, including investment, annual and } \\
\text { financing costs }\end{array}$} \\
\hline & \multicolumn{5}{|c|}{ Electricity sector only } & \multirow[b]{2}{*}{$\begin{array}{l}\text { Electricity } \\
\text { sector, } \\
\text { including } \\
\text { cost } \\
\text { savings in } \\
\text { heating and } \\
\text { transport }\end{array}$} & \multicolumn{5}{|c|}{ Electricity sector only } & \multirow[b]{2}{*}{$\begin{array}{l}\text { Electricity } \\
\text { sector, } \\
\text { including } \\
\text { cost } \\
\text { savings in } \\
\text { heating and } \\
\text { transport }\end{array}$} \\
\hline & $\begin{array}{l}\text { Large-scale } \\
\text { generation }\end{array}$ & $\begin{array}{l}\text { Small-scale } \\
\text { generation }\end{array}$ & $\begin{array}{l}\text { Transmission, } \\
\text { distribution, } \\
\text { and inter- } \\
\text { connectors }\end{array}$ & $\begin{array}{c}\text { Electric } \\
\text { heating and } \\
\text { transport }\end{array}$ & Total & & $\begin{array}{l}\text { Large-scale } \\
\text { generation }\end{array}$ & $\begin{array}{l}\text { Small-scale } \\
\text { generation }\end{array}$ & $\begin{array}{l}\text { Transmission } \\
\text {, distribution, } \\
\text { and inter- } \\
\text { connectors }\end{array}$ & $\begin{array}{c}\text { Electric } \\
\text { heating and } \\
\text { transport }\end{array}$ & Total & \\
\hline \multicolumn{13}{|c|}{ Market Rules } \\
\hline 2020 & 48 [75] & $0[0]$ & 31 [48] & $42[66]$ & 122 [188] & 83 [128] & 263 [406] & $0[0]$ & 57 [89] & 124 [192] & 444 [687] & 274 [424] \\
\hline 2030 & 107 [165] & $0[0]$ & $51[80]$ & 180 [278] & 338 [523] & 186 [288] & $491[760]$ & $0[0]$ & 105 [163] & 444 [686] & 1040 [1609] & 527 [815] \\
\hline 2040 & $152[235]$ & $0[0]$ & $63[98]$ & $311[481]$ & $526[814]$ & $263[407]$ & $668[1032]$ & $0[0]$ & $134[207]$ & $797[1232]$ & $1598[2471]$ & $727[1102]$ \\
\hline 2050 & $182[282]$ & $0[0]$ & $70[110]$ & $453[701]$ & $707[1092]$ & $314[486]$ & $815[1260]$ & $0[0]$ & $170[263]$ & $1182[1827]$ & $2167[3350]$ & 841 [1273] \\
\hline \multicolumn{13}{|c|}{$\begin{array}{l}\text { Central Co- } \\
\text { ordination }\end{array}$} \\
\hline 2020 & $53[82]$ & $0[0]$ & 29 [44] & $42[64]$ & $123[190]$ & 81 [125] & 261 [404] & $0[0]$ & $52[81]$ & 125 [193] & 439 [678] & $259[401]$ \\
\hline 2030 & 102 [158] & $0[0]$ & $43[66]$ & $274[423]$ & 418 [647] & $197[304]$ & 471 [728] & $0[0]$ & $91[141]$ & 627 [969] & 1189 [1838] & 524 [810] \\
\hline 2040 & 131 [203] & $0[0]$ & 50 [77] & $402[621]$ & $582[900]$ & 266 [411] & 617 [954] & $0[0]$ & $110[170]$ & 1024 [1583] & 1751 [2707] & 689 [1065] \\
\hline 2050 & 154 [239] & $0[0]$ & 53 [82] & 533 [825] & $741[1145]$ & 321 [496] & 737 [1139] & $0[0]$ & 137 [213] & 1384 [2140] & 2258 [3491] & $781[1208]$ \\
\hline \multicolumn{13}{|c|}{$\begin{array}{l}\text { Thousand } \\
\text { Flowers }\end{array}$} \\
\hline 2020 & $41[64]$ & $19[30]$ & 19 [29] & $33[51]$ & $112[173]$ & 59 [92] & 232 [359] & $41[63]$ & $41[63]$ & 116 [180] & $430[664]$ & $237[366]$ \\
\hline 2030 & 72 [112] & $35[54]$ & $34[53]$ & $295[456]$ & $436[675]$ & 183 [283] & $376[582]$ & $124[191]$ & 80 [123] & $657[1016]$ & 1237 [1912] & 515 [797] \\
\hline 2040 & $93[144]$ & 45 [69] & $42[64]$ & 459 [709] & 638 [987] & 265 [410] & 467 [721] & 198 [306] & 98 [152] & $1114[1722]$ & 1877 [2901] & 698 [1079] \\
\hline 2050 & $112[173]$ & $54[83]$ & $43[67]$ & $651[1006]$ & 860 [1329] & $353[546]$ & 541 [837] & $262[405]$ & 123 [190] & 1564 [2418] & $2490[3850]$ & 833 [1287] \\
\hline
\end{tabular}




\subsection{Generation costs per unit of electricity}

As the three pathways differ in their electricity demand levels, generation costs per unit of electricity, calculated on the basis of levelised costs of electricity, is the most suitable indicator to compare the electricity generation mix costs. Whether the carbon price is considered as a part of the price or not, Central Coordination has the lowest costs per MWh of generated electricity in 2050 (Table 5). Yet, the difference to Market Rules is very small. Thousand Flowers has a substantially higher costs per MWh. This is not surprising because it envisions significant deployment of such costly technologies as micro-CHP and community CHP. Yet, in terms of total system costs, such an expensive electricity generation mix is compensated by cost savings due CHPs replacing gas boilers for heating.

Table 5. Generation costs per unit of electricity, evaluated as weighted average levelised cost of electricity, in $£(2010) / M W h[U S \$(2010) / \mathrm{kWh}]$

\begin{tabular}{|c|c|c|c|c|c|c|c|c|c|c|c|c|}
\hline \multirow[b]{2}{*}{ Year } & \multicolumn{4}{|c|}{ Market Rules } & \multicolumn{4}{|c|}{ Central Co-ordination } & \multicolumn{4}{|c|}{ Thousand Flowers } \\
\hline & 2020 & 2030 & 2040 & 2050 & 2020 & 2030 & 2040 & 2050 & 2020 & 2030 & 2040 & 2050 \\
\hline $\begin{array}{l}\text { Excluding } \\
\text { carbon price }\end{array}$ & $\begin{array}{c}80.3 \\
{[12.4]}\end{array}$ & $\begin{array}{c}85.3 \\
{[13.2]}\end{array}$ & $\begin{array}{c}71.4 \\
{[11.0]}\end{array}$ & $\begin{array}{l}50.3 \\
{[7.8]}\end{array}$ & $\begin{array}{c}75.3 \\
{[11.6]}\end{array}$ & $\begin{array}{c}79.7 \\
{[12.3]}\end{array}$ & $\begin{array}{c}73.5 \\
{[11.4]}\end{array}$ & $\begin{array}{l}48.9 \\
{[7.6]}\end{array}$ & $\begin{array}{c}94.0 \\
{[14.5]}\end{array}$ & $\begin{array}{c}97.6 \\
{[15.1]}\end{array}$ & $\begin{array}{c}93.6 \\
{[14.5]}\end{array}$ & $\begin{array}{l}58.7 \\
{[9.1]}\end{array}$ \\
\hline $\begin{array}{l}\text { Including } \\
\text { carbon price }\end{array}$ & $\begin{array}{c}88.2 \\
{[13.6]}\end{array}$ & $\begin{array}{c}90.9 \\
{[14.1]}\end{array}$ & $\begin{array}{c}76.2 \\
{[11.8]}\end{array}$ & $\begin{array}{l}54.8 \\
{[8.5]}\end{array}$ & $\begin{array}{c}82.4 \\
{[12.7]}\end{array}$ & $\begin{array}{c}83.3 \\
{[12.9]}\end{array}$ & $\begin{array}{c}77.6 \\
{[12.0]}\end{array}$ & $\begin{array}{l}51.8 \\
{[8.0]}\end{array}$ & $\begin{array}{l}100.2 \\
{[15.5]}\end{array}$ & $\begin{array}{c}99.9 \\
{[15.4]}\end{array}$ & $\begin{array}{c}95.9 \\
{[14.8]}\end{array}$ & $\begin{array}{l}59.7 \\
{[9.2]}\end{array}$ \\
\hline
\end{tabular}

The overall trend for the generation cost per MWh is to peak at 2030 and then decrease. This is caused by the assumptions of: (i) learning effects that reduce investment costs in low-carbon technologies (investment cost assumptions are reported in the Supplementary Material A) and (ii) reduced use of increasingly expensive fossil fuels and reduced greenhouse gas emissions in a low-carbon system. The difference between the costs with or without carbon costs diminishes towards 2050, assuming the transition to a low-carbon system.

For additional detail into the cost differences between the pathways, Table B.1 in the Supplementary Material B compares the technology-specific costs per MWh of generated electricity with the whole mix generation costs per MWh (including carbon price). Based on the typology of power plants as base 
load, shoulder load or peak load plants, insights on the economic feasibility are gathered. Electricity generated by unabated fossil fuel power stations (coal ASC, coal IGCC and gas CCGT) that are primarily base load plants becomes very costly after 2030. This is caused by rising fossil fuel and carbon prices and lower capacity factors of these technologies in a low-carbon system with a high share of intermittent renewables. Without additional support, such plants would not be competitive for supplying base load and shoulder load electricity demand, as the costs become too high. Coal and gas plants with CCS become less competitive towards 2050 as well due to rising fossil fuel prices and the cost of emitting the assumed $10 \%$ of produced $\mathrm{CO}_{2}$ that is not captured. These results indicate a changing role for such large-scale technologies with fossil fuels in a low-carbon system with intermittent renewables.

If policy support, other than carbon price, is not considered, the stylised comparison in Table B1 still shows that some low-carbon technologies would require support to become integrated into the system. In all the three pathways tidal, wave and hydro power as well as biomass plants have comparatively high electricity generation costs for base load and shoulder load plants. Solar power is not competitive until 2030, but later becomes competitive due to technology learning effects. Electricity generated by micro-CHP Stirling engines has very high costs due to high investment costs throughout the whole appraisal timeframe. Even with policy support, substantial deployment of such power plants in the case of Thousand Flowers may be over-ambitious.

Table B1 generally raises economic feasibility concerns over the envisioned governance narratives, especially because investment in large-scale power plants that would run with low capacity factors would hardly be realistic. As discussed in Section 2.2, three technical feasibility models that originally informed the development of the quantitative pathways used a predefined, constant merit order instead of modelling electricity generation on the basis of technology costs and detailed dispatch (Trutnevyte et al., 2014). For example, these models prioritised the full integration of intermittent renewable electricity and the same time assumed substantial deployment of coal and gas CCS, which would need to operate with low load factors. However, economic feasibility of costly CCS plants, used with low load factors, would in reality limit the 
attractiveness of these plants to investors, unless specific policies are enacted. Such considerations point to the need for simultaneous, rather than sequential, linking of energy-economy-environment models and governance narratives, as demonstrated by Trutnevyte (2014).

\subsection{Sensitivity analysis}

\subsubsection{Sensitivity to fossil fuel prices}

Figure 3 presents the fossil fuel price sensitivity results in terms of cumulative total costs for the electricity sector, including generation, transmission, distribution and interconnectors, and excluding or including electric heating and transport. Overall, the total system costs are not affected substantially, because in the low-carbon energy future that is depicted in the three pathways, the role of fossil fuels diminishes by 2050. Although fossil fuel prices affect the individual costs of electricity generation or cost savings, they do not affect the ranking of the pathways as compared to the central case. If cost savings are not accounted for, Thousand Flowers under all sensitivity cases remains as the most costly pathway. However, the higher the fossil fuel prices, the smaller the cost gap between Thousand Flowers and the other two pathways.

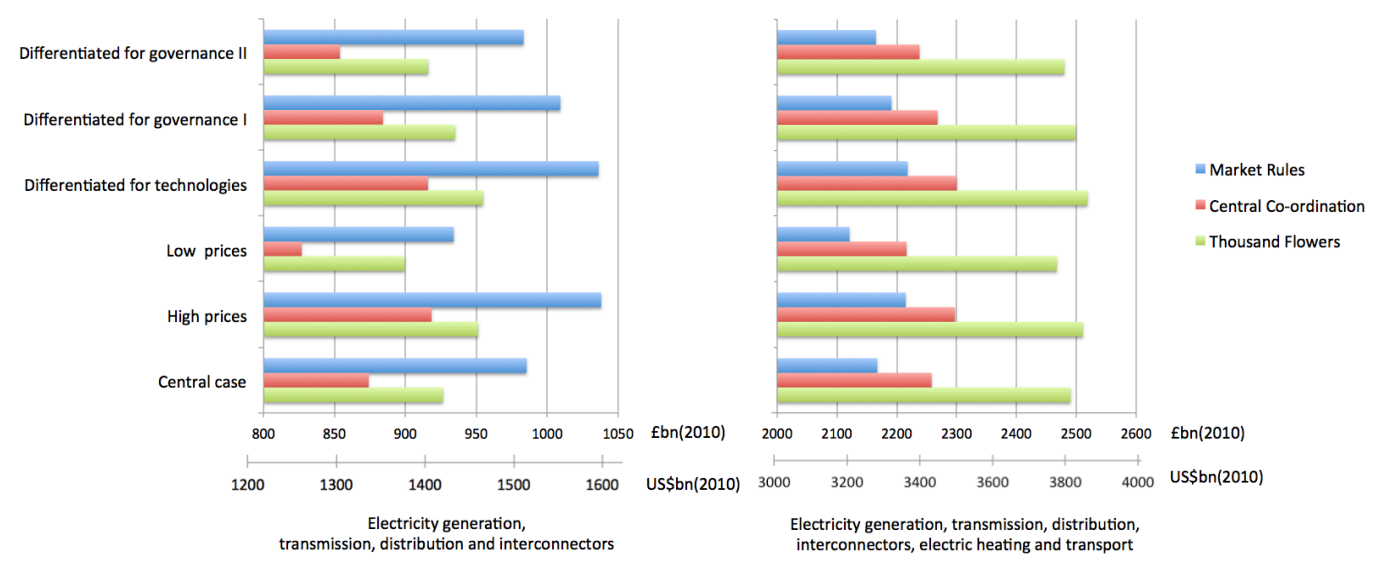

Figure 3. Sensitivity of cumulative total costs in 2050 to fossil fuel prices and financing cost assumptions 


\subsubsection{Sensitivity to financing costs}

Figure 3 presents results of the sensitivity analysis to different financing cost assumptions. If different financing costs are assumed for each generation technology, the cumulative total costs increase in 2050 for all three pathways. This is primarily caused by the fact that financing costs were increased for several technology types (see Table 3) as compared to the central case, especially for the comparatively risky low-carbon technologies. Yet, the cumulative total costs increase the most for Market Rules and Central Co-ordination, which both include numerous large-scale, low-carbon technologies with assumed high financing costs, especially CCS, marine and tidal. If the role of policies, described in the governance narratives (Section 2.2), are 'translated' into lower financing cost assumptions in these pathways, then the total system costs decrease. That is, if policies can reduce investment risks, then the total system costs are reduced too due to lower interest rates that energy companies receive. Of course, this transfers some risk from private firms to the public sector.

Even with different financing cost assumptions, the ranking of the three pathways does not change in terms of total costs of electricity sector or total costs of generation, transmission and distribution. If cost savings are accounted for (not reported in Figure 3), there are still no major differences between the pathways. In the case of cumulative total costs for generation, transmission and distribution in Figure 3, the largest decline in total costs is seen in the case of Central Co-ordination. Central Co-ordination assumes that the central UK government will implement firm policies to support low-carbon generation, especially by issuing contracts to specific types of generation. Such policies could substantially reduce the investment risks (Oxera, 2011) and hence could reduce the total system costs by 1-2\%. If stable policies are implemented in other pathways as well (Figure 3), then their costs also decrease. 


\section{Discussion}

\subsection{Comparison of the results with existing cost estimates}

In recent years, increasing concerns over the affordability of the ambitious UK emission mitigation targets (similar to the debate in other G20 economies) has led to numerous cost appraisals (DECC, 2014a; Ernst \& Young, 2009; LSE, 2012; National Grid, 2013b; Ofgem, 2009, 2010; Trutnevyte, 2014). Although with its focus on the role of governance, the cost appraisal performed in this paper is unique, its findings are compared in Table 6 with other aforementioned studies for validation. As every study used different appraisal boundaries and methodologies as well as reported different types of results, the detailed comparison is conducted only in terms of investment costs in generation, transmission and distribution.

Table 6. Comparison of the cost appraisal results with cost estimates from other studies (T\&D - transmission and distribution)

\begin{tabular}{|c|c|c|c|c|}
\hline Study & Timeframe & $\begin{array}{c}\text { Cumulative investment, fbn } \\
\text { [US\$bn] }\end{array}$ & $\begin{array}{c}\text { Annual investment level, } \\
\text { fbn/year [US\$bn/year] }\end{array}$ & $\begin{array}{c}\text { Wholesale electricity price, } \\
\text { f/MWh [USc/kWh] }\end{array}$ \\
\hline $\begin{array}{l}\text { Ofgem (2009, } \\
2010)\end{array}$ & $2009-2020$ & $\begin{array}{l}\text { Generation and T\&D: } 110-130 \\
{[170-201]}\end{array}$ & $\begin{array}{l}\text { Generation and T\&D: } 10-12 \\
{[15-19]}\end{array}$ & $\begin{array}{l}60[9.3] \text { in } 2020 \\
65-75[10.0-11.6] \text { in } 2025\end{array}$ \\
\hline $\begin{array}{l}\text { UK Energy Bill } \\
\text { (DECC, 2012) }\end{array}$ & $2012-2020$ & $\begin{array}{l}\text { Generation: } 75 \text { [116] } \\
\text { T\&D: } 35[54]\end{array}$ & $\begin{array}{l}\text { Generation: } 9 \text { [14] } \\
\text { T\&D: } 4 \text { [16] }\end{array}$ & - \\
\hline $\begin{array}{l}\text { London School of } \\
\text { Economics (2012) }\end{array}$ & $2012-2020$ & Generation: 330 [510] & $\begin{array}{l}\text { Generation: } 18 \text { [27.8] } \\
T \& D: 1.6[2.5]\end{array}$ & - \\
\hline $\begin{array}{l}\text { National Grid } \\
(2013 b)\end{array}$ & $2013-2020$ & Generation: 49 [76] & Generation: 7 [11] & $\begin{array}{l}80-100[12.4-14.5] \text { in } \\
2010-2035\end{array}$ \\
\hline $\begin{array}{l}\text { Ernst \& Young } \\
(2009)\end{array}$ & $2016-2025$ & $\begin{array}{l}\text { Generation: } 80[124] \\
T \& D: 14[22]\end{array}$ & $\begin{array}{l}\text { Generation: } 9 \text { [13.9] } \\
\text { T\&D: } 1.5[2.3]\end{array}$ & - \\
\hline \multirow{3}{*}{$\begin{array}{l}\text { DECC2050 } \\
\text { Calculator (DECC, } \\
2014 a)^{*}\end{array}$} & $2010-2020$ & Generation: 53-196 [82-303] & Generation: 5-20 [8-31] & - \\
\hline & $2010-2030$ & Generation: $163-668$ [252-1032] & Generation: 8-33 [12-51] & - \\
\hline & $2010-2050$ & Generation: 357-1916 [552-2962] & Generation: 9-48 [14-74] & - \\
\hline \multirow{2}{*}{$\begin{array}{l}\text { Trutnevyte } \\
\text { (2014) }\end{array}$} & $2010-2020$ & Generation: 40-115 [62-178] & Generation: 4-12 [16-19] & - \\
\hline & $2010-2050$ & Generation: 114-253 [176-391] & Generation: 3-6 [5-9] & \\
\hline \multirow{3}{*}{$\begin{array}{l}\text { Cost appraisal } \\
\text { results } \\
\text { (Central case) }\end{array}$} & $2010-2020$ & $\begin{array}{l}\text { Generation: 48-60 [75-94] } \\
\text { T\&D: 19-31 [29-48] }\end{array}$ & $\begin{array}{l}\text { Generation: 5-6 [8-9] } \\
\text { T\&D: 2-3 [3-5] }\end{array}$ & $82-100[12.1-15.5]$ in 2020 \\
\hline & $2010-2030$ & $\begin{array}{l}\text { Generation: } 102-107 \text { [158-165] } \\
\text { T\&D: } 34-51[53-80]\end{array}$ & $\begin{array}{l}\text { Generation: 5-6 [8] } \\
\text { T\&D: 2-3 [3-4] }\end{array}$ & $83-100[12.9-15.4]$ in 2030 \\
\hline & $2010-2050$ & $\begin{array}{l}\text { Generation: } 138-152 \text { [213-235] } \\
\text { T\&D: 42-63 [64-96] }\end{array}$ & $\begin{array}{l}\text { Generation: 4-5 [6-7] } \\
\text { T\&D: 1-2 [2] }\end{array}$ & $55-60[8.5-9.2]$ in 2050 \\
\hline
\end{tabular}


Cumulative investment costs for electricity generation (Table 6) in the case of Market Rules, Central Co-ordination and Thousand Flowers are comparable, but a little lower than the estimates from existing studies. The values are lower for two reasons. First, when the data on actual retirement time of existing power plants were not available, the retirement rates were used. As a substantial number of UK power plants will have to retire by 2020 (DECC, 2012), there will be a peak in investment levels by then, but the presented appraisal could not capture it due to the non-availability of some of the planned retirement dates. Second, most of the other studies do not state explicitly whether their cost estimates have been discounted, what discount rate and which year's currency have been used. The undiscounted cumulative investment costs of the three pathways are $£ 81-89 b n$ (US\$125-138bn) by 2020, £168-188bn (US\$260290 bn) by 2030 and $£ 286-352$ bn (US $\$ 442-545 b n$ ) by 2050 . Assuming that some of the existing estimates have not been discounted, the results of this cost appraisal would fall in the comparable range with other existing estimates.

The values of annual investment costs also fall within the ranges, set by the other studies. The upper values of $£ 5-6 \mathrm{bn} /$ year (US\$8-9bn/year) in all three pathways look ambitious. Historically, the investment after privatisation, between 1997 and 2004, was rather low due to high spare capacity in the system and varied from roughly $£ 3-4 \mathrm{bn} /$ year (US\$5-6bn/year). In the recent years, due to Renewables Obligations the investment increased to up to $£ 8 \mathrm{bn} /$ year (US\$12bn/year) in 2011 (DECC, 2012b). Ernst \& Young (2013) reported that between 2010 and 2013, £29bn (US\$45bn/year) of investment was announced in renewable energy generation. Therefore, such annual investment levels in the three pathways as compared to the historical values may be realistic, if the UK commits to low-carbon transition.

The annual and cumulative investment costs in transmission, distribution and interconnectors for the three pathways are in the same range as in other studies. None of the other studies report total system costs with comparable appraisal boundaries, but a technology-by-technology comparison for heating and transport of the total system costs from Table 4 with DECC (2014a) yields similar results for the same end-use technology uptake levels. 


\subsection{Limitations and future research needs}

This analysis provides a novel attempt to gather insights into the role of governance in shaping the UK electricity system transition and its costs. The analysis will be extended in the future to provide a more comprehensive understanding of links between governance and the whole energy system costs. The first aim will be to extend the system boundaries (Section 2.3.1). The current transition pathways would benefit from additional detail on electricity use efficiency improvements through behavioural and technical measures. If such data were available, then investment and total costs of efficiency and demand reduction, and the value of lost load, could be evaluated. The current version of the appraisal also includes only the costs of heat producing equipment, such as CHPs, heat pumps, resistive heating or gas boilers, but does not account for any auxiliary equipment, such as heat storage, installation of heating systems, etc. The total costs are evaluated accounting for cost savings in non-electric types of heating and transport. This is a relatively simplistic accounting that does not require a more detail modelling of the whole heat supply portfolio and the whole vehicle mix. In order to undertake a more systematic analysis, an extension of the system boundaries to include heating and transport could be conducted by energy system models, such as UK MARKAL (Dodds et al., 2014; Ekins et al., 2011) and UKTM (UCL Energy Insitute, 2014). These models are purely marketbased models that do not consider governance narratives, but they can provide additional insights by disaggregating the vehicle fleet (Dodds and Ekins, 2014; Dodds and McDowall, 2014) and the housing stock (Dodds, 2014). In addition, interactions between the low-carbon transition in the electricity sector and the rest of the energy system as well as the associated costs could then be captured.

In terms of the cost appraisal boundaries, the presented appraisal focuses only on annual system costs and levelised costs of electricity, but does not evaluate electricity companies' revenues, investment attractiveness, short-run or long-run marginal prices, consumer prices, and cost savings. When the pathways are further fleshed out with more detail on hour-by-hour dispatch or by adding a baseline pathway, such an extension of the appraisal would become feasible. The presented appraisal also focuses only on monetary costs and does not analyse 
either externalities (costs to the environment, society at large etc.) or benefits. These pathways would have different impacts on the environment, key stakeholders and wider society. While some of these impacts can be monetised (e.g. wider macroeconomic impacts), the cost appraisal is only one assessment pillar and a broader interdisciplinary appraisal needs to be conducted (Stagl, 2006, 2007). Moreover, as the three pathways differ in their governance arrangements (organisation structure, number and role of the key actors etc.), it is very likely that these pathways would have different transaction costs and would affect the key system actors differently. A detailed assessment of the costs and cost savings borne by different actors may reveal that some market participants are significantly disadvantage or require guarantees and even crosssubsidies. Thus, the cost appraisal should be disaggregated in the future to reflect on the implications and attractiveness of the pathways to the various actors.

The current version of the appraisal is based on deterministic values of technology costs, fuel prices and other assumptions, but does not model other types of parametric uncertainty than fossil fuel prices or financing costs. As future technological improvements, technology costs and wider international developments, such emission mitigation commitments, may have a substantial impact on the appraisal results, a systematic uncertainty analysis should be conducted. Such systematic uncertainty analysis could adopt the story-andsimulation approach in order to capture interactions among multiple parametric assumptions (Alcamo, 2008; Schweizer and Kriegler, 2012). Stories, that are internally consistent combinations of parametric assumptions, would then be developed and used for sensitivity analysis. Such stories would help capturing how increased carbon price is coupled to faster technology improvements of low-carbon technologies or how changes in fossil fuel prices affect global inflation rates, raw material costs and eventually the investment costs of the electricity technologies. Yet, the sensitivity analysis in Section 3.3 shows that the appraisal results do not vary substantially because of the fixed quantitative pathways and the generally diverse technology portfolios.

In fact, these fixed pathways do not allow for addressing uncertainties in technology deployment levels due to co-evolution of governance and the 
electricity system. A more systematic modelling attempt that links governance narratives directly to an energy-economy-environment model, by-passing the translation of each governance narrative into a single quantitative pathway, should be undertaken. However, the majority of existing models still acknowledge costs as the key (and often - the only) transition driver and thus do not leave enough space for accounting for the role of governance and decisions of the key actors, beyond costs. For example, optimisation-based energy-economyenvironment models, such as UK MARKAL or UKTM (UCL Energy Insitute, 2014), are limited to the analysis of cost-optimal pathways only. Thus, these models can hardly capture non-cost drivers and softer governance implications that underpin energy transition. Although various policies or actor preferences can be enforced in these models as constraints or tailored parametric assumptions, the energy system is still assumed to respond in the cost-optimal way. This glosses over the uncertainty that system response may not only depend on costs, but also on other drivers and softer governance as multi-level transitions theory argues. The EXPANSE model (Trutnevyte, 2013; Trutnevyte, 2014; Trutnevyte and Strachan, 2013), which captures near-optimal energy pathways in addition to the cost-optimal one, is especially suitable for an integrated analysis of governance and costs. Trutnevyte (2014) proved the concept of translating the three narratives Market Rules, Central Co-ordination and Thousand Flowers into a thousand of diverse quantitative pathways each in order to account for uncertainties in technology deployment. This approach now needs to be refined and completed.

\section{Conclusions and policy implications}

The conventional economic view identifies costs as the key determinant of energy transition. The multi-level perspective to socio-technical transitions advocates an alternative viewpoint that places governance and the choices of key actors as the crucial influences. Such distinct analytical perspectives give inflexible insights to policy makers, with findings dependent on either a cost optimising world-view or an actor-decision world-view. This paper has 
combined the two approaches in a novel analysis of UK electricity system transition and its costs under alternate governance logics.

The analysis shows that market-led transition, as described in the Market Rules narrative, follows the most investable pathway and has the lowest investment costs. Given policies, such as carbon price floor, market could deliver the UK electricity system transition that meets the 'trilemma' of low-carbon, affordable and secure system, but the benefit of low investment comes at the expense of certainty of successfully addressing the 'trilemma'. If government would take a more active role in steering the transition by, for example, issuing contracts for specific low-carbon electricity technologies, as described in the Central Co-ordination narrative, this would increase the likelihood of achieving low-carbon and secure system. In addition, if such governmental control elements can be enacted and maintained, they could lead to a synergy between achieving these policy goals and simultaneously reducing total system costs. However, this would require higher investment levels and some of the investment risk would need to be faced by the government. The society-led transition, envisioned in the Thousand Flowers narrative about bottom-up, proactive engagement of the civil society, would come at the expense of higher investment and total system costs, but would ensure wider participation of the society at large. Although the investment challenge would be higher than in the market-led and government-led pathways, this society-led pathway would spread this challenge across a wider range of investors, including households.

Policy makers, tasked with understanding and governing electricity system transition, shall acknowledge such synergies and trade-offs between governance and costs, because some of these trade-offs need to be made. First, if delivery of the investment is left to the market mechanisms, the investment levels may be comparatively low to prevent the failure of achieving the 'trilemma' of low-carbon, affordable and secure system. If stricter governmental policies would be enacted to mobilize higher investment levels, then achievement of energy policy goals would be more likely and the total system costs in the long term could be simultaneously reduced. Yet, the investment needs would be higher than in the case of free market and this challenge would need to be addressed by the government. The ease of this challenge by spreading 
the investment across a wider range of actors, including ESCO companies and end-use consumers (e.g. households), would come at the expense of higher investment and total costs, but would bring the benefits of higher societal engagement and awareness of energy challenges.

Such synergies and trade-offs between governance and costs reach beyond the electricity generation, transmission and distribution to the sectors of heating and transport too. In fact, the identified trade-offs and synergies are dealt with across multiple governmental departments for energy, environment, business, transport, communities and others, who have different mandates. Thus, cross-departmental discussion and decision making is necessary.

\section{Acknowledgements}

This work was conducted as a part of the Realising Transition Pathways consortium project, supported by the UK Engineering and Physical Sciences Research Council (Grant EP/K005316/1). The authors are solely responsible for the analysis and views in this paper. The authors thank the other members of the Realising Transition Pathways project and the preceding Transition Pathways project, who developed the narratives and the quantitative pathways; a full list of the consortium members is available on the Realising Transition Pathways website (2013). The authors are especially grateful to Tim Foxon for his comments on the manuscript and Elizabeth Robertson, Damie Emanuel-Yusuf, Marko Aunedi, John Barton, Matthew Leach and Áine O'Grady for refining the quantitative pathways. Constructive comments of four anonymous reviewers are much appreciated too.

\section{References}

Alcamo, J., 2008. Chapter Six The SAS Approach: Combining Qualitative and Quantitative Knowledge in Environmental Scenarios, in: Joseph, A. (Ed.), Developments in Integrated Environmental Assessment. Elsevier, pp. 123-150.

Anandarajah, G., Strachan, N., Ekins, P., Kannan, R., Hughes, C., 2009. Pathways to a Low Carbon Economy: Energy Systems Modelling. UKERC Energy 2050 Research Report 1. UKERC, London. 
Arapostathis, S., Carlsson-Hyslop, A., Pearson, P.J.G., Thornton, J., Gradillas, M., Laczay, S., Wallis, S., 2013. Governing transitions: Cases and insights from two periods in the history of the UK gas industry. Energy Policy 52, 25-44.

Barnacle, M., Robertson, E., Galloway, S., Barton, J., Ault, G., 2013. Modelling generation and infrastructure requirements for transition pathways. Energy Policy.

Barton, J., Huang, S., Infield, D., Leach, M., Ogunkunle, D., Torriti, J., Thomson, M., 2013. The evolution of electricity demand and the role for demand side participation, in buildings and transport. Energy Policy 52, 85-102.

Bhattacharyya, S.C., Timilsina, G.R., 2010. A review of energy system models. International Journal of Energy Sector Management 4, 494-518.

Blyth, W., McCarthy, R., Gross, R., 2014. UKERC Energy Strategies Under Uncertainty: Financing the Power Sector - Is the Money Available? UKERC Report UKERC/WP/FG/2014/004. UKERC, London.

Bolton, R., Foxon, T., 2013. Negotiating the energy policy 'trilemma' - an analysis of UK energy governance from a socio-technical systems perspective, IGov Workshop: Theorising Governance Change for a Sustainable Economy,, London.

Bolton, R., Foxon, T.J., 2015. A socio-technical perspective on low carbon investment challenges - Insights for UK energy policy. Environmental Innovation and Societal Transitions 14, 165-181.

Boston, A., 2013. Delivering a secure electricity supply on a low carbon pathway. Energy Policy 52, 55-59.

Brealey, R.A., Myers, S.C., 2000. Principles of Corporate Finance. 6th edition. McGraw Hill Higher Education, -.

DECC, 2010. Statutory Security of Supply Report. A report produced jointly by DECC and Ofgem. DECC, London. 
DECC, 2011. A brief guide to the carbon valuation methodology for UK policy appraisal. DECC, London.

DECC, 2012. Electricity Market Reform: policy overview. UK Department of Energy and Climate Change, London.

DECC, 2013. DECC Fossil Fuel Price Projections. DECC, London, UK.

DECC, 2014a. The 2050 Calculator.

DECC, 2014b. DECC 2050 Pathway Calculator Excel Model. Excel version 3.4.6. , DECC.

Dodds, P.E., 2014. Integrating housing stock and energy system models as a strategy to improve heat decarbonisation assessments. Applied Energy 132, 358369.

Dodds, P.E., Ekins, P., 2014. A portfolio of power-trains for the UK: an energy systems analysis. International Journal of Hydrogen Energy 39, 13941-13953.

Dodds, P.E., Keppo, I., Strachan, N., 2014. Characterising the Evolution of Energy System Models Using Model Archaeology. Environ Model Assess, 1-20.

Dodds, P.E., McDowall, W., 2014. Methodologies for representing the road transport sector in energy system models. International Journal of Hydrogen Energy 39, 2345-2358.

Ekins, P., Anandarajah, G., Strachan, N., 2011. Towards a low-carbon economy: scenarios and policies for the UK. Climate Policy 11, 865-882.

Ernst \& Young, 2009. Securing the UK's energy future-seizing the investment opportunity. An update to the Ernst \& Young study: 'Securing the UK's energy future-meeting the financing challenge' Ernst \& Young, London.

Ernst \& Young LLP, 2013. Powering the UK 2013: Empowering UK growth, jobs and energy users through continues investment. EYGM Limited, UK. 
European Commission, 2008. Guide to Cost Benefit Analysis of Investment Projects. European Commission, Brussels.

Foxon, T.J., 2013. Transition pathways for a UK low carbon electricity future. Energy Policy 52, 10-24.

Foxon, T.J., Hammond, G.P., Pearson, P.J.G., 2010. Developing transition pathways for a low carbon electricity system in the UK. Technological Forecasting and Social Change 77, 1203-1213.

Foxon, T.J., Pearson, P.J.G., Arapostathis, S., Carlsson-Hyslop, A., Thornton, J., 2013. Branching points for transition pathways: assessing responses of actors to challenges on pathways to a low carbon future. Energy Policy 52, 146-158.

Geels, F.W., 2002. Technological transitions as evolutionary reconfiguration processes: a multi-level perspective and a case-study. Research Policy 31, 12571274.

Geels, F.W., Schot, J., 2007. Typology of sociotechnical transition pathways. Research Policy 36, 399-417.

Goldthau, A., 2012. From the State to the Market and Back: Policy Implications of Changing Energy Paradigms. Global Policy 3, 198-210.

Hammond, G.P., Howard, H.R., Jones, C.I., 2013. The energy and environmental implications of UK more electric transition pathways: A whole systems perspective. Energy Policy 52, 103-116.

Hammond, G.P., O'Grady, A., 2013. The Implications of Upstream Emissions from the Power Sector. Proceedings of the Institution of Civil Engineers - Energy in press.

Hammond, G.P., Pearson, P.J.G., 2013. Challenges of the transition to a low carbon, more electric future: From here to 2050. Energy Policy 52, 1-9.

Hara, T., 2014. A Variety of Near-Optimal Solutions in the Vehicle Mix Optimization Model, International Energy Workshop 2014, Beijing, China. 
Helm, D., 2003. Energy, the State, and the Market: british Energy Policy 1979. Oxford University Press, Oxford.

HM Treasury, 2011. The Green Book: Appraisal and Evaluation in Central Government. TSO, London.

Hughes, N., Strachan, N., 2010. Methodological review of UK and international low carbon scenarios. Energy Policy 38, 6056-6065.

Hughes, N., Strachan, N., Gross, R., 2013. The structure of uncertainty in future low carbon pathways. Energy Policy 52, 45-54.

LSE, 2012. Energy and the economy: The 2030 outlook for UK businesses. A report comissioned by RWE npower. LSE, London, RWE npower.

National Grid, 2013a. RIIO Transmission \& Gas Price Control 1. Ofgem Initial Proposals. National Grid, London.

National Grid, 2013b. UK Future energy scenarios: UK gas and electricity transmission. National Grid, London.

Ofgem, 2009. Project discovery. Energy market scenarios. Ofgem, London.

Ofgem, 2010. Project Discovery Energy Market Scenarios Update.

Oxera, 2011. Discount rates for low-carbon and renewable generation technologies. Prepared for the Committee on Climate Change. London, Oxera.

Pantaleo, A., Candelise, C., Bauen, A., Shah, N., 2014. ESCO business models for biomass heating and CHP: Profitability of ESCO operations in Italy and key factors assessment. Renewable and Sustainable Energy Reviews 30, 237-253.

Pearson, P., Watson, J., 2011. UK Energy Policy, 1980-2010 A history and lessons to be learned. IET and Parliamentary Group for Energy Studies, London.

Pfenninger, S., Hawkes, A., Keirstead, J., 2014. Energy systems modeling for twenty-first century energy challenges. Renewable and Sustainable Energy Reviews 33, 74-86. 
Pudjianto, D., Djapic, P., Aunedi, M., Gan, C.K., Strbac, G., Huang, S., Infield, D., 2013. Smart control for minimizing distribution network reinforcement cost due to electrification. Energy Policy 52, 76-84.

Realising Transition Pathways, 2013. Realising Transition Pathways: Whole systems analysis for a UK more electric low carbon energy future.

Robertson, E., Anderson, L., Galloway, S., 2012a. The impact of distributed generation in Scotland (on the energy system, to consumers and to national emission levels, CIGRÉ, Montreal, Quebec, Canada.

Robertson, E., Galloway, S., Ault, G., 2012b. The Impact of Wide Spread Adoption of High Levels of Distributed Generation in Domestic Properties, IEEE Power \& Energy Society General Meeting, San Diego, US.

Schmidt, T.S., 2014. Low-carbon investment risks and de-risking. Nature Clim. Change 4, 237-239.

Schweizer, V.J., Kriegler, E., 2012. Improving environmental change research with systematic techniques for qualitative scenarios. Environmental Research Letters 7, 1-14.

Short, W., Packey, D.J., Holt, T., 1995. A manual for the economic evaluation of energy efficiency and renewable energy technologies. National Renewable Energy Laboratory, Golden.

Stagl, S., 2006. Multicriteria evaluation and public participation: The case of UK energy policy. Land Use Policy 23, 53-62.

Stagl, S., 2007. SDRN rapid research and evidence review on emerging methods for sustainability valuation and appraisal. SDNR, -.

Strbac, G., Aunedi, M., Pudjianto, D., Djapic, P., Gammons, S., Druce, R., 2012. Understanding the balancing challenge. DECC, London. 
Swart, R.J., Raskin, P., Robinson, J., 2004. The problem of the future: Sustainability science and scenario analysis. Global Environmental ChangeHuman and Policy Dimensions 14, 137-146.

Transition Pathways, 2012. Transition Pathways releases new narratives for pathways.

Trutnevyte, E., 2013. EXPANSE methodology for evaluating the economic potential of renewable energy from an energy mix perspective. Applied Energy $111,593-601$.

Trutnevyte, E., 2014. Linking governance storylines with the D-EXPANSE model to explore the power system transition pathways, in: Ames, D.P., Quinn, N.W.T., Rizzoli, A.E. (Eds.), 7th International Congress on Environmental Modelling and Software Proceedings, San Diego, USA.

Trutnevyte, E., Barton, J., O'Grady, Á., Ogunkunle, D., Pudjianto, D., Robertson, E., 2014. Linking a storyline with multiple models: A cross-scale study of the UK power system transition. Technological Forecasting and Social Change 89, 26-42.

Trutnevyte, E., Stauffacher, M., Scholz, R.W., 2012. Linking stakeholder visions with resource allocation scenarios and multi-criteria assessment. European Journal of Operational Research 219, 762-772.

Trutnevyte, E., Strachan, N., 2013. Nearly perfect and poles apart: investment strategies into the UK power system until 2050, International Energy Workshop 2013, Paris.

UCL Energy Insitute, 2014. UK TIMES.

Usher, W., Strachan, N., 2013. An expert elicitation of climate, energy and economic uncertainties. Energy Policy 61, 811-821.

Williams, J.H., DeBenedictis, A., Ghanadan, R., Mahone, A., Moore, J., Morrow, W.R., Price, S., Torn, M.S., 2012. The Technology Path to Deep Greenhouse Gas Emissions Cuts by 2050: The Pivotal Role of Electricity. Science 335, 53-59. 
